\title{
Chapter 23 \\ Food, Sustainability, and Science Literacy in One Package? Opportunities and Challenges in Using Aquaponics Among Young People at School, a Danish Perspective
}

\author{
Bent Egberg Mikkelsen and Collins Momanyi Bosire
}

\begin{abstract}
The call for sustainable food production and consumption has led to an increased interest and new policy measures to support the circular economy and climate-smart farming practices. The merits of aquaponics and closed-loop nutrient cycling systems are increasingly being examined in terms of sustainable productivity in various settings including urban environments. Aquaponics also has the potential to be applied as a learning tool for people of all ages but especially for young people at school. This chapter studies the potential of aquaponics to teach food and science literacy and the use of the technology as an educational tool in primary school. The chapter draws on data from the Growing Blue \& Green (GBG) program carried out in cooperation among Aalborg University, Copenhagen, municipal schools and their teachers and a private aquaponic enterprise. The chapter draws on three empirical studies including an exploratory study on the educational opportunities at school, a feasibility study carried out among teachers, as well as the educational Growing Blue \& Green (eGBG) study, in which a digital-based regulation component was added. The conclusion is that low-cost versions of aquaponics have considerable potential for supportive learning in elementary school. Preliminary findings furthermore suggest that fitting the setup with easy-to-install intelligent sensors and devices offers the opportunity to provide learning about food, sustainability, and a basic understanding of the control and management of biological systems in one package.
\end{abstract}

Keywords Aquaponics · Sustainability education $\cdot$ Science literacy $\cdot$ Food literacy · Education · Primary school

\author{
B. E. Mikkelsen ( $\square)$ \\ Integrated Food Studies, Aalborg University Copenhagen, Copenhagen, Denmark \\ e-mail: bemi@learning.aau.dk \\ C. M. Bosire \\ Department of Learning \& Philosophy, Aalborg University, Copenhagen, Denmark
}




\subsection{Introduction}

Sustainable food production and consumption are important societal challenges. Growing populations, scarcity of arable land, and urbanization are all important factors in this area, leading to a growing interest in new sustainable food production technologies, which are not necessarily confined to maritime or rural settings. Aquaponics is one of these technologies that has received increased attention, in particular, since it can easily be applied also in urban environments. These new technologies, including aquaponics, also offer new opportunities as learning tools for people of all ages, but it is particularly appealing for young people at school. This chapter reports on the findings from the educational Growing Blue \& Green (GBG) program that has been developed and tested in educational settings in the Greater Copenhagen area. Additional studies also suggest that there appears to be potential for using aquaponics as a key way of learning about sustainable food production in a wide spectrum of academic disciplines at school since it can readily be integrated into the existing educational curriculum. A few studies have examined the application of aquaponics in an educational context. Graber et al. (2014) studied the potential of aquaponics as a food production method for urban areas teaching seventh-grade pupils sustainability issues in science classes. The idea behind the concept was to introduce and train students on "systems thinking" by combining fish and plant growing. Junge et al. (2014) showed that the students' ability to think in a systematic way improved significantly as a result. The study also suggested that building on social learning in groups the students developed greater teamwork skills. However, apart from these examples, aquaponics literature is relatively limited and most of the available articles have focused on the technological aspects of the systems. This chapter attempts to fill this knowledge gap by exploring the opportunities for integrating aquaponic technology into school learning and to uncover some of the constraints as well as the opportunities.

The chapter draws on three empirical cases, where aquaponics has been applied in primary school settings in the Greater Copenhagen area. This includes an exploratory study on the educational opportunities at school (Bosire et al. 2016), a feasibility study carried out among teachers (Bosire and Sikora 2017), as well as the insights from the first part of an educational Growing Blue \& Green study (Toth and Mikkelsen 2018).

The aim of this chapter is thus to introduce and discuss educational aquaponic interventions in which aquaponics is used in an elementary school in Denmark and to discuss how theory can be taken into practice. The chapter discusses the potential of aquaponics to be able to contribute to the fostering of a deeper learning about urban, sustainable food production among young school children in school settings, as well as the potentials for creating digital literacy through the addition of a selfregulating digital sensing and maintenance tool, i.e., the eGBG tool. 


\subsection{Conceptual Foundation}

Supporting Sustainable Development (SD) of the food system through educational efforts can be expected to be a good investment, as school children are the future policy makers and producers.

According to Shephard (2008), educators and particularly higher educators have traditionally focused on the cognitive domain of learning with no much emphasis being put on primary education. We hold the view that using appropriate learning tools at primary school level can be an essential pillar to bringing about long-term positive change in societies. These can be realized though alternative learning and teaching approaches, different from traditional deductive approaches such as "learning by doing" and "experiential learning" pioneered by Dewey (1997) in his work experience and education. In our research work, we present a type of extracurricular dimensional perspective, where we add to pupils' learning outcomes by tapping into the affective domain, which focuses on interests, attitudes, appreciations, values, changing behaviors, and emotional sets or biases (Shephard et al. 2015). Practical aquaponics promises to deliver a hands-on problem-based inductive learning tool for education.

Study cases all build on the idea of Service Learning (SL), where students use academic knowledge to address community needs, and the knowledge triangle (education, research, and innovation), which are part of the teaching at the Integrated Food Studies (IFS) program at Aalborg University (Mikkelsen and Justesen 2015). The IFS also uses Problem-Based Learning (PBL), where learning is approached with open-ended problems with no absolute right answer, as well SL approaches. SL is a pedagogical approach that is rooted in PBL as well as in the experiential learning approach (McKay-Nesbitt et al. 2012). Using the SL approach, students are expected to become involved in projects based on the needs, wishes, and demands of local communities. The recent interest in reforming educational practices and strategies makes the use of aquaponics an important component in the educational context timely and relevant. Additionally, the use of inductive methods such as PBL and discipline-based learning (Wood 2003: Armstrong 2008) as well as experiential learning (Beard 2010; McKay-Nesbitt et al. 2012), where everyday life problems and questions are used to inform the learning process, is spreading. These concepts are all favorable for aquaponic teaching. Furthermore, the idea of SL is compatible with the aquaponic teaching concept and the recent Danish School Reform (Danish Ministry of Education 2014) that present guidelines on how to integrate the practical and theoretical aspects of the curriculum.

While there are several aquaponic systems that can be supplied by manufacturers and/or bespoke systems designed by consultants, aquaponic technology in principle is rather simple. The basic principles can thus be well understood by students, and the systems can be designed, built, and monitored by students using a range of materials and methods, ranging from the basic to the sophisticated. Taking this 


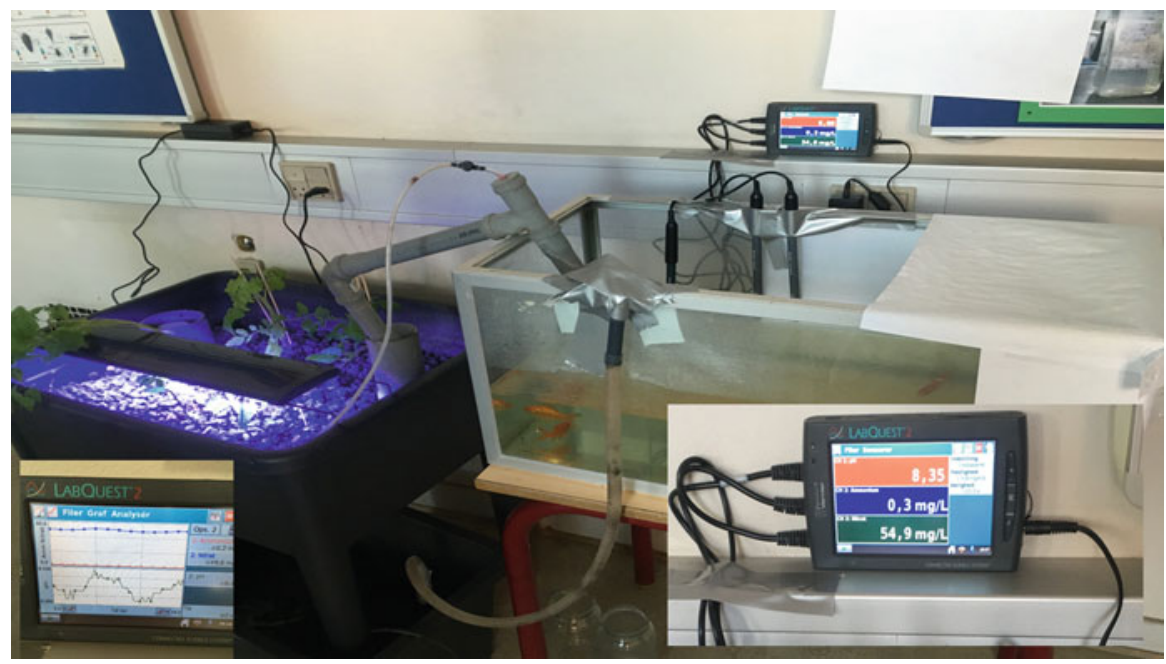

Fig. 23.1 The aquaponic learning and experimental mock-up. The illustration shows the setup including aquarium fish tank and the monitoring devices that are used to measure the equilibrium of the whole system. The last part is the core of the learning goal for students. (Pictures: courtesy of Lija Gunnarsdottir)

premise, aquaponics is thus a technology that is highly suited to the knowledge triangle approach. Education can be enhanced through the creation of links between the three sides of the knowledge triangle, i.e., education, research, and innovation. Innovative thinking on how education for sustainability could be implemented using practical educational tools leads the educator toward aquaponics: a food production method which is essentially a symbiotic integration of two mature disciplines recirculating aquaculture and hydroponics in one production system, where the live fish generate nutrients for plant production. A simple aquaponic system unit, such as the one shown in Fig. 23.1, was set up at an elementary school in Copenhagen. The figure illustrates some of the basic components used with a brief detail on its working principle: a simple aquarium where water in the fish tank is kept at a constant height through appropriate design for the comfort of the fish. Through some pumping action from a sump tank situated below the grow bed, excess water containing fish waste is cycled through plant grow beds, where bacteria and other microbes are hosted.

The sump and grow bed act together as mechanical and biofilters, respectively, by removing solids and dissolved waste.

The setup in Fig. 23.1 illustrates a practical educational example, focusing on sustainability since it provides a practical example of how the goals set out under Sustainable Development Goals (SDGs) in UN Agenda 2030 for SD can be addressed (UN 2015b). Goal number 2, which targets ending hunger, achieving food security and improved nutrition, and promoting sustainable agriculture, and goal number 4 , which focuses on ensuring inclusive and equitable quality education 
and the promotion of lifelong learning opportunities for all (UN 2015b). These crucial issues can be included in the Problem-Based Learning (PBL) approach that has been developed in the GBG case. Based on a shared firm belief in having technological solutions for the problems of contemporary food systems, the GBG approach contributes to a demonstration of "ecological modernization" in food production processes. Through the development of the didactic for the eGBG themes of sustainability and food literacy, it became clear that for such a system to bring about change, there is a need for the right platform through which knowledge and skills can be exchanged among young people and their teachers in the school setting.

Other studies have shown that the lack of food and nutrition literacy among young people is of growing concern (Vidgen and Gallagos 2014; Dyg and Mikkelsen 2016). This is particularly concerning, as the conventional ways of food production and the current persistent drivers of science and technology have fueled unsustainable global exploitation of earth's resources leading to numerous challenges within the food system (FAO 2010; UNDP 2016). In addition, the increase in world population and the rapid urbanization have overloaded the food system. The United Nations predicts that world population will increase by more than 1 billion people within the next 15 years, reaching 8.5 billion in 2030 . Of these, the majority (66\%) is forecasted to be living in cities by the year 2050 (UN 2015a). These trends in combination with the growth in unhealthy eating habits and nutrition-related disorders have made a new approach to food nutrition and agriliteracy at school imperative.

The insights from the GBG project and the results from numerous interviews with both teachers and students showed that the successful application of aquaponic technology is dependent on the careful planning and maintenance of the system. The digital version of the GBG - the eGBG - was developed to address these challenges and to use the related opportunities in promoting digital literacy in school. The idea of the eGBG takes inspiration from the idea of self-regulation in biological systems. It is conceptually based on the idea of autopoiesis: referring to a system capable of reproducing and maintaining itself. The term first introduced in 1972 by biologists Maturana and Varela (1980) describes the self-maintaining chemistry of living cells, and ever since then, the concept has been applied in a wide array of fields such as cognition, systems theory, and sociology. In the eGBG study, illustrated by the setup and components in Fig. 23.2, water quality, temperature, dissolved oxygen, $\mathrm{CO} 2, \mathrm{pH}$, ammonia, and nitrite content are measured with sensors using an electronic and digitalized setup, followed by appropriate automated regulation and adjustments to the required or set levels. This system used alongside a basic maintenance regime better enables children to learn Information and Communications Technology (ICT), together with Science, Technology, Engineering, and Mathematics (STEM) subjects in addition to a wider understanding of sustainable urban farming and animal welfare practices. The eGBG minimizes human error and reduces the amount of critical resources such as the physical labor and hours that would otherwise be required for the care and maintenance of a balanced aquaponic system. 


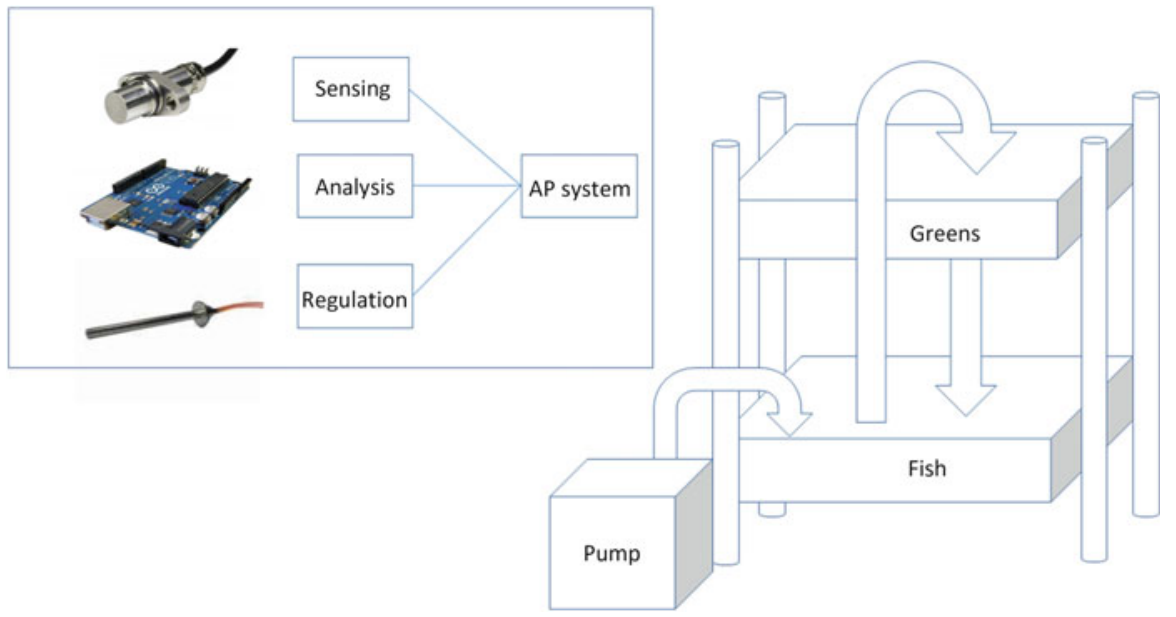

Fig. 23.2 The experimental eGBG setup. The illustration shows the two parts of the system. The aquaponic system itself and the measuring devices and the minicomputer used to follow the biological condition of the eGBG system

\subsection{Methods}

In the context of this chapter, three data sources were used including (a) an exploratory study on the educational opportunities at school (Bosire et al. 2016), (b) a feasibility study carried out among teachers (Bosire and Sikora 2017), and (c) the eGBG study (Toth and Mikkelsen 2018).

The first study (a) was carried out as an exploration of the opportunities and challenges of using aquaponics as an educational tool. The study aimed at investigating to what extent it makes sense to use aquaponics in school teaching. Data from three $(\mathrm{N}=3)$ independent qualitative interviews were collected. The informants were (1) a biology teacher engaged in natural science teaching at primary school; (2) a consultant entrepreneur, which is an aquaponic expert, too; and (3) one local aquaponic bio-farmer. The data analysis procedure was inspired by the future workshop approach (Jungk and Müllert 1987), leading to a categorization and evaluation according to the three categories of critique, fantasy, and strategy.

In the second study (b), a feasibility study was carried out at the Blågaard Public School located within the Copenhagen Municipality in cooperation with two biology teachers and a physics teacher and with approval from the school administration. The local aquaponic bio-farmer and expert was also involved. A low-cost aquaponic facility for teaching was developed using a simple do-it-yourself (DIY) food production system and off-the-shelf components. The idea for this design and construction was to illustrate that this kind of technology can readily be undertaken, and it is not only for advanced urban growing but that it also has potential to be used as a science-teaching tool in humbler settings such as a local school. Since the budget of 
the school is limited, the overall goal was to complete the project at low cost and to carefully fit the system within the requirements of the existing curricula.

In the third study (c), a digital component was added to an improved version of the aquaponic system and the eGBG was introduced. The eGBG is a learning program based on simple aquaponics, and it is designed to create learning insights among adolescents. The program's special focus is on teaching principles of sustainable food production in cities and at the same time to facilitate ICT learning. The program's didactics is aimed at showing how a biological system like aquaponics can be controlled, maneuvered, and self-regulated using sensors and feedback mechanisms. This is done by connecting sensors that measure temperature, $\mathrm{pH}$, and nutrient balance via a digital interface such as Arduino. The eGBG developed a simple urban farming tool based on a learning package for schools where students can learn about this technology in biology classes. By studying how the sensors work, they have the ability to learn how ICT can be integrated to monitor and control a living biological system.

The eGBG educational program can be used both in an interdisciplinary course with ICT as a theme or in the subjects of biology, physics, and chemistry. The components of the eGBG are for a low-cost aquaponic system that has been developed for the school context as described previously. Some of the key elements were supplied by BioTeket, which is a company with a social and cultural remit with an emphasis on environmental technology. BioTeket offers a series of workshops and events, giving the citizens of Copenhagen an opportunity to gain experience with sustainable urban life. The assembly was done under the company's technical supervision. According to the national curricula, ICT in elementary school is taught not as a stand-alone subject, but in a transversal manner spanning several subjects. Combining smart and sensor-based control and biological system therefore seems straightforward for this requirement. Urban farming technologies require a monitoring system with a multitude of sensors since maintaining a system in balance requires continuous measurement of temperature, $\mathrm{pH}$, etc. To meet this requirement, the eGBG was developed in cooperation between Aalborg University, a municipal school in Albertslund, and the enterprise BioTeket. The development process was configured as an action research study where data was collected along with the development process.

\subsection{Findings and Discussion}

1. From the first study, the findings showed that visions of a new way of teaching with inclusion of the modern technology could be perceived as an advantage in influencing transformational processes at school. Nevertheless, this process requires some critical, practical, and theoretical considerations for implementation of the system to make it successful and sustainable in the long term. Some of the positive issues from the users' perspectives included a wide range of application in the subjects of biology, mathematics, science, and more. Reduction 
pollution and efficient resource usage; flexibility of the system setup, e.g., on rooftops; and the production of (organic-like*) twin products (fish and plant foods). Potential limitations included time constraints, lack of financial resources, as well as the need for frequent care and maintenance. (* In the EU, current legislation provides that only vegetal produce grown in soil may be considered "organic." This is not the case, e.g., in the USA, where aquaponic produce can be grown organically and legally sold as being organic.)

2. From the second study (b), the feasibility study, the experiences of the study indicated that the learning concept, the overall idea, and the didactics fit well into the educational curricula and also with the projects that the school had already planned to undertake in the field of sustainability. The experience showed that such teaching needs to be carefully planned well ahead of time. Furthermore, the idea of a knowledge triangle approach, bringing service learning, university research, a small enterprise, and the learning staff into an informal project and innovation network, is a fruitful way of organizing the undertaking. In addition, the initiative enjoys the support of the municipality that sees entrepreneurship and innovative learning approaches as important objectives.

3. The third study (c), the eGBG study, showed that the school was supportive and already had newly purchased sensors to measure $\mathrm{pH}$, temperature, $\mathrm{CO}_{2}$, and dissolved oxygen (DO). Therefore, the data could be conducted with minimal new effort for training, as the teaching staff were already well prepared to collect data digitally. The school, at the point of project startup, was already planning to measure nitrate and ammonia using the sensors, since the basic concept of the teaching was to increase knowledge, skill, and competency in relation to the nitrogen cycle. The idea of creating aquaponic technology and applying it in the teaching was readily accepted by the school since the neighboring school already had that kind of an AP system up and running.

Acknowledgments Thanks to biology teachers Mette and Else at Blågård School in Copenhagen Municipality, to Lilja Gunnarsdottir and the teachers at Herstedlund school, and to Inge Christensen from the Nature Centre in Albertslund municipality. Thanks also to Viktor Toth, a student at Integrated Food Studies, Aalborg University, for providing data from the eGBG study. Thanks also to Tomasz Sikora and Kathrine Breidahl from the Integrated Food Studies that participated in the fieldwork. Thanks also to the owner and CEO Lasse Antoni Carlsen of Bioteket, Copenhagen, for providing components and guidance in developing the GBG program.

\section{References}

Armstrong EG (2008) A hybrid model of problem-based learning. In: Boud D, Feletti G (eds) The challenge of problem-based learning. Routledge, London

Beard C (2010) The experiential learning toolkit: blending practice with concepts. Kogan Page, London 
Bosire CM, Sikora TA (2017) Blue-green farms of the future: using aquaponics at Primary School to Foster sustainable development (Master thesis). Retrieved from http://projekter.aau.dk/ projekter/files/259876456/Collins_Bosire_Tomasz_Sikora_Blue_Green_Farms_of_the_ Future_EMT.pdf

Bosire CM, Breidahl KS, Sikora TA, Mikkelsen BE (2016) Education for sustainability and food literacy - assessing opportunities and challenges for using aquaponics among young people at Schools. In: Mikkelsen BE, Ofei KT, Tvedebrink TDO, Romani AQ, Sudzina F (eds) Proceedings from 10th international conference on culinary arts and sciences, July 5-7th 2017 Aalborg University Copenhagen - Exploring Future Foodscapes, Published by Captive Food Studies. AAU Aalborg, p 250-267

Danish Ministry of Education (2014) Improving the public school- overview of reform of standards in the Danish Public School (primary and lower secondary education) The Danish Ministry of Education. Available at http: www.uvm.dk/publicschool. ISBN (Electronic version): 978-87603. Accessed 24 May 2016

Dewey J (1997) Experience and education. Kappa Delta Pi, Touchstone. (Original work published 1938)

Dyg PM, Mikkelsen BE (2016) Cooperation models, motivation and objectives behind farm-school collaboration: case insights from Denmark. Int J Soc Agric Food 23(1):41-62

Food and Agriculture Organization (2010) Sustainable diets and biodiversity: directions and solutions for policy, research and action. International scientific symposium, biodiversity and sustainable diets united against hunger. Rome, Italy, 3-5 November 2010

Graber A, Antenen N, Junge R (2014) The multifunctional aquaponic system at ZHAW used as research and training lab. Available at http://pd.zhaw.ch/publikation/upload/207534.pdf. Accessed 22 May 2016

Junge R, Wilhelm S, Hofstetter U (2014) Aquaponic in classrooms as a tool to promote system thinking. Available at http://www.adam-europe.eu/prj/10804/prj/Paper_VIVUSConf_Junge_ et_al.pdf. Accessed 23 May 2016

Jungk R, Müllert N (1987) Future workshops: how to create desirable futures. Institute for Social Inventions, London

Maturana H, Varela F (1980) Realization of the living. In: Boston Studies in the Philosophy of Science, vol 42. Reidel, Dordrecht

McKay-Nesbitt J, DeMoranville CW, McNally D (2012) A strategy for advancing social marketing: social marketing projects in introductory marketing courses. J Soc Mark 2(1):52-69. https://doi. org/10.1108/20426761211203256

Mikkelsen BE, Justesen J (2015) Multi disciplinarily in higher educations for the captive foodscape profession: case of Denmark. In: Proceedings of the international conference on culinary arts and eating in society. Montclair State University, Montclair, pp 262-263

Shephard K (2008) Higher education for sustainability: seeking affective learning outcomes. Int J Sustain High Educ 9(1):87-98

Shephard K, John H, Brent L, Miranda M, Sheila S, Liz S, Mick S, Mary F, Tim J, Lynley D (2015) Seeking learning outcomes appropriate for 'education for sustainable development' and for higher education. Assess Eval High Educ 40(6):855-866

Toth V, Mikkelsen BE (2018) Growing blue \& green - exploring the potentials of teaching sustainable urban food the smart way. Protocol for extended master thesis at Integrated Food Studies, Aalborg University

United Nations (2015a) World population prospects, the 2015 revision vol. 2: Demographic Profiles. Available at http://esa.un.org/unpd/wpp/Publications/Files/WPP2015_Volume-II-Demo graphic-Profiles.pdf. Accessed 8 Mar 2016

United Nations (2015b) Transforming our world: the 2030 agenda for sustainable development. Available at https://sustainabledevelopment.un.org/post2015/transformingourworld. Accessed 3 Mar 2017 
United Nations Development Programme (2016) Overview: human development report 2016 human development for everyone (online). Available at http://hdr.undp.org/sites/default/files/ HDR2016_EN_Overview_Web.pdf. Accessed 24 Mar 2017

Vidgen HA, Gallegos D (2014) Defining food literacy and its components. Appetite 76:50-59

Wood DF (2003) Problem based learning. BMJ 326(7384):328-330. https://doi.org/10.1136/bmj. 326.7384 .328

Open Access This chapter is licensed under the terms of the Creative Commons Attribution 4.0 International License (http://creativecommons.org/licenses/by/4.0/), which permits use, sharing, adaptation, distribution and reproduction in any medium or format, as long as you give appropriate credit to the original author(s) and the source, provide a link to the Creative Commons licence and indicate if changes were made.

The images or other third party material in this chapter are included in the chapter's Creative Commons licence, unless indicated otherwise in a credit line to the material. If material is not included in the chapter's Creative Commons licence and your intended use is not permitted by statutory regulation or exceeds the permitted use, you will need to obtain permission directly from the copyright holder. 